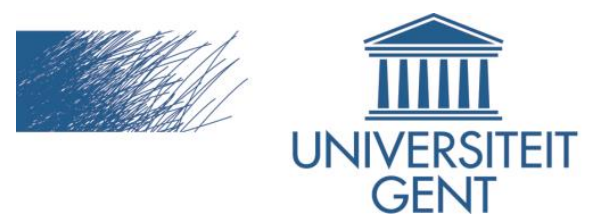

biblio.ugent.be

The UGent Institutional Repository is the electronic archiving and dissemination platform for all UGent research publications. Ghent University has implemented a mandate stipulating that all academic publications of UGent researchers should be deposited and archived in this repository. Except for items where current copyright restrictions apply, these papers are available in Open Access.

This item is the archived PEER-REVIEWED AUTHOR-VERSION of:

Title: A discrete spatial choice model of burglary target selection at the house-level Authors: Vandeviver, C., Neutens, T., Van Daele, S., Geurts, D., \& Vander Beken, T. In: Applied Geography, doi: 10.1016/j.apgeog.2015.08.004 Link to the article: http://www.sciencedirect.com/science/article/pii/S0143622815001976

To refer to or to cite this work, please use the citation to the published version:

Vandeviver, C., Neutens, T., van Daele, S., Geurts, D., \& Vander Beken, T. (2015). A discrete spatial choice model of burglary target selection at the house-level. Applied Geography, 64, 24-34. doi: 10.1016/j.apgeog.2015.08.004 


\section{A discrete spatial choice model of burglary target selection at the house-level}

\section{Abstract}

This article studies how burglars select a house to burglarize. We draw on the rational choice perspective to investigate how burglars select a target by relying on house-related attributes to optimize a combination of perceived rewards, efforts and risk. It extends current applications of the discrete spatial choice framework to burglary target selection by adopting the house as the spatial unit of analysis and studies burglars' target selection process in a larger and more diverse study area than that of earlier studies. Using data on 650 residential burglaries and on approximately 500,000 residential properties in the Belgian province East Flanders, we consider a discrete spatial choice model of burglary target selection to establish which house-related attributes influence burglars' target selection process. Our findings demonstrate that terraced houses, houses without a garage, houses that have not been outfitted with a central heating and/or air-conditioning system and houses nearby burglars' residences are more likely to be selected. Overall, our analysis suggests that burglars rely on effort-related attributes to distinguish between targets while higher perceived rewards actually decrease the odds of a house being burglarized. Risk-related attributes are unimportant for burglars' target choice.

\section{Highlights}

- We study the burglary target selection process at the house-level

- We apply the discrete choice model with a choice set of over 500,000 houses

- Higher perceived rewards reduce the odds of burglary

- Lower perceived efforts increase the odds of burglary

- Burglars do not rely on risk-related information to distinguish between targets

\section{Keywords}

Crime; Burglary; Location choice; Target selection; Discrete choice; Rational choice perspective

\section{Introduction}

Recent years have seen an increase of geospatial research into crime in general and burglary in particular. Numerous studies are interested in exploring spatiotemporal variations in burglary (Andresen \& Malleson, 2013; de Melo, Matias, \& Andresen, 2015; D. Johnson, 2013; Ye, Xu, Lee, Zhu, $\& W u, 2015)$ and examining how features of the physical environment affect the spatial patterning of burglary (Breetzke, 2012; Wu, et al., 2015). One distinct strand of geographical criminological research that has recently gained traction applies the discrete spatial choice framework to study where burglars offend and what makes them prefer one target over another (Bernasco, 2006, 2010b; Bernasco, Johnson, \& Ruiter, 2015; Bernasco \& Nieuwbeerta, 2003, 2005; Clare, Fernandez, \& Morgan, 2009; Townsley, et al., 2014; Townsley, Birks, Ruiter, Bernasco, \& White, 2015). While these studies have advanced the understanding of offenders' spatial decision-making processes, thus far they have not touched upon the core of burglary target selection: how do offenders pick a particular house to burglarize. The spatial resolution of existing applications of the discrete spatial choice approach to crime target selection does not yet fully align with the theoretical and empirical understanding of burglars' target selection process. Prior work has exclusively focused on intermediary outcomes and used larger spatial units of analysis such as neighborhoods or postal code 
areas to model burglars' target selection process, even though burglars ultimately select a house to burglarize.

This paper addresses this shortcoming and seeks to establish which attributes at the house-level influence offenders' decision when selecting a residential property as a burglary target. In answering this question, the present study introduces several advancements over prior work into burglars' spatial decision-making processes. First, this is the first discrete spatial choice study that models the target selection process of burglars using the house as the spatial unit of analysis. Previous studies modeled this process as a choice between larger spatial units such as residential neighborhoods (Bernasco, 2006, 2010b; Bernasco \& Nieuwbeerta, 2005; Clare, et al., 2009; Townsley, et al., 2014). These applications are not erroneous as such, since offenders are assumed to rely on a spatially structured hierarchical target selection process in which they initially select a larger area such as a neighborhood before gradually narrowing down their choice (Bernasco, 2010a, p. 117), but they fail to appreciate that burglars ultimately burglarize a house. In other words, the spatial resolution of existing applications of the approach is not aligned with the outcome of offenders' spatial choice behavior and the decisions they are expected to make when looking for a particular burglary target. In addition, the use of fine-grained spatial units of analysis such as the house that is burglarized has the advantage that it addresses the modifiable areal unit problem and reduces the risk of aggregation bias (Bernasco, Block, \& Ruiter, 2012; Oberwittler \& Wikström, 2009). Aggregation bias and spatial heterogeneity may impact the outcome of geospatial criminological research. Whenever possible smaller spatial units of analysis are to be preferred over larger spatial units of analysis (Andresen \& Malleson, 2011; Oberwittler \& Wikström, 2009). Since micro-places more accurately measure the environment in which the offender acts, it is preferable to conduct geospatial criminological research at the most fine-grained spatial resolution available. With respect to burglary, there is little debate that the house is naturally the smallest spatial unit of analysis available (Bernasco, 2010a). Essentially, burglary is about an offender finding a suitable house to burglarize and committing his offence within a clearly confined space. In this study, we consider a discrete spatial choice model of burglary target selection in which every burglar can choose among 503,589 residential properties in a Belgian province to pick a burglary target.

Furthermore, the current application of the discrete spatial choice approach focuses on the importance of house attributes for offenders' choice of crime site. Previous crime location choice studies focused on environmental attributes at higher levels of spatial aggregations such as neighborhood affluence or area accessibility. This has resulted in numerous studies convincingly establishing the role and importance of area characteristics in offenders' target selection process, including a recent effort to systematically replicate the effects of environmental attributes on burglary crime location choice in three cross-national study regions (e.g., Townsley, et al., 2014). Due to the lack of widely available small-scaled spatial data, no discrete spatial choice studies have been able to focus on the role of house-level characteristics in burglars' target selection process. Instead of replicating the results of previous crime location choice studies, this study models offenders' target choices as a combination of house-related attributes and in doing so combines the analytical framework of discrete spatial choice with earlier insights from a well-established research tradition that applies offender interviews, ethnography and experiments to understand burglary target selection (e.g., Nee \& Taylor, 2000). 
Finally, the proposed discrete spatial choice model is operationalized in a study area that is larger and more diverse than that of earlier implementations. The study area comprises the entire province of East Flanders (Belgium), a densely urbanized polycentric study area with a population of approximately 1.5 million inhabitants distributed across 12 cities and 53 towns. This study area is much larger in terms of population size, surface area and available alternatives than that of cognate burglary studies, including Bernasco and Nieuwbeerta (2005), Bernasco (2006, 2010b), and Clare, et al. (2009) that have primarily relied on crime data from a single city or metropolitan area. With the exception of Bernasco, et al. (2015), no discrete choice studies of crime target selection have yet looked at a single study area that contains multiple cities and towns.

This article is structured as follows. The next section starts with a brief discussion of the rational choice perspective and burglary target selection. The methodology section discusses the discrete spatial choice framework as our preferred method of analysis. In the subsequent section, we present the study area and the data. This is followed by a section that addresses our research hypotheses. The main findings are presented in the results section. We conclude with a discussion of the results in light of the current knowledge base regarding burglars' target selection process and outline avenues for future work.

\section{Burglars' target selection process: balancing reward, effort and risk}

The rational choice perspective (Cornish \& Clarke, 1986b) is one of the dominant frameworks for understanding offenders' behavior, including offender spatial decision-making and their target selection process (Bernasco, et al., 2015). It is a heuristic tool for looking at offending behavior and the decisions that underlie and shape this behavior. The perspective is rooted in microeconomics and offers a lens for understanding how and where individual offenders decide to exploit perceived criminal opportunities and commit their offences. From within the rational choice perspective, it is argued that offenders are rational insofar that their behavior is purposive and expresses their intention to benefit themselves (Cornish \& Clarke, 1986a, 2006). The perspective proposes that offenders balance the costs and benefits of their decisions and that when they are confronted with a choice, they will select that particular alternative from a larger set of alternatives that appears to be the best outcome of that balancing act of costs and benefits (Bottoms, 2007, p. 541; Elffers, 2004, p. 184). Offenders aim to maximize their benefits while keeping the anticipated costs to a minimum (Pettiway, 1982; Van Koppen \& Jansen, 1998). To do so, they rely on environmental and situational cues related to rewards, efforts and risks (Cornish \& Clarke, 2006).

Consistent with the arguments contained within this framework, previous research highlights that a range of target-specific, environmental attributes related to rewards, efforts and risks affect burglars' target choices. Ethnographic research and offender interviews suggest that burglars are driven by monetary gain and favor apparently wealthier targets over poorer ones since these offer better chances of making a greater financial profit (Bennett \& Wright, 1984; Maguire \& Bennett, 1982; Rengert \& Wasilchick, 1985). Furthermore, burglars have indicated that they select dwellings based on certain visible cues that signal target profitability such as the size of the house and its general upkeep (Nee \& Taylor, 2000; Wright \& Decker, 1994). This allows us to articulate our first hypothesis that higher perceived rewards increase the likelihood that a house is burglarized.

Given the circumstances, offenders exert as little effort as possible to achieve their goal and in doing so are very similar to other individuals in their daily activities (Zipf, 1949). One important strategy to 
minimize effort is to select nearby targets instead of remote ones. This is known as the distancedecay effect and is widely reported in journey-to-crime research (Bernasco, 2006; Pyle, Hanten, Williams, Pearson, \& Doyle, 1974; Turner, 1969; Wiles \& Costello, 2000). Another strategy reported in research is to select targets that can easily be broken into because they have multiple points of entry, preferably on the side or back of the building (Maguire \& Bennett, 1982), or because the doors and window frames are weathered or made of inferior materials (Cromwell, Olson, \& Avary, 1991; Shaw \& Gifford, 1994; Wright, Logie, \& Decker, 1995). We state the second hypothesis that lower perceived efforts increase the likelihood that a house is selected for burglary.

Finally, offenders want to minimize the risk while committing their offence. Burglars have repeatedly expressed their dislike for houses that have an increased chance of detection by neighbors such as terraced houses (Bennett \& Wright, 1984; Cromwell, et al., 1991) and prefer targets that offer multiple escape routes in case of detection (Maguire \& Bennett, 1982). For instance, the lack of escape routes is cited by offenders as a reason to bypass apartment buildings altogether when looking for burglary targets (Bennett \& Wright, 1984, pp. 65-66). We formulate the third hypothesis that lower perceived risk increases the likelihood that a house is burglarized.

\section{Data}

For our analysis, we have combined recorded crime data on burglaries in East Flanders from the Belgian Federal Police with data on residential houses from the Belgian Land Registry to study burglars' target selection process. These datasets provide us with information on the decisionmakers (burglars), their choices (burglarized houses), and their choice set (all other non-burglarized houses in East Flanders). In this section, we discuss the study area, the characteristics of the recorded crime data, the selection of burglary cases, the computation of the considered offender's-home-tocrime-site distance measure, and the residential housing data.

\subsection{East Flanders and its recorded crime data}

The study area spans East Flanders (see Fout! Verwijzingsbron niet gevonden.), a north-western province in Belgium that borders the Netherlands in the north. It covers nearly $3,000 \mathrm{~km}^{2}$ and has a population of approximately 1.5 million. It is a densely urbanized area that includes 12 cities and 53 towns. The third most populous city of Belgium, Ghent, is centrally located within the province. ${ }^{1}$ East Flanders has several large industrial and economic zones as well as a small-sized international seaport, situated in Ghent and stretching in northeasterly direction up to the Dutch border. It has a dense road network and is crossed by three highways, making it possible to reach all municipalities by car in less than two hours. Most municipalities in the study area are linked by an extensive and widely used public transport and railway network.

\footnotetext{
${ }^{1}$ Strictly speaking, Ghent is the second most populous city of Belgium preceded by Antwerp. However, we treat the Brussels metropolitan area (consisting of multiple municipalities) as a singly city with over a million inhabitants..
} 


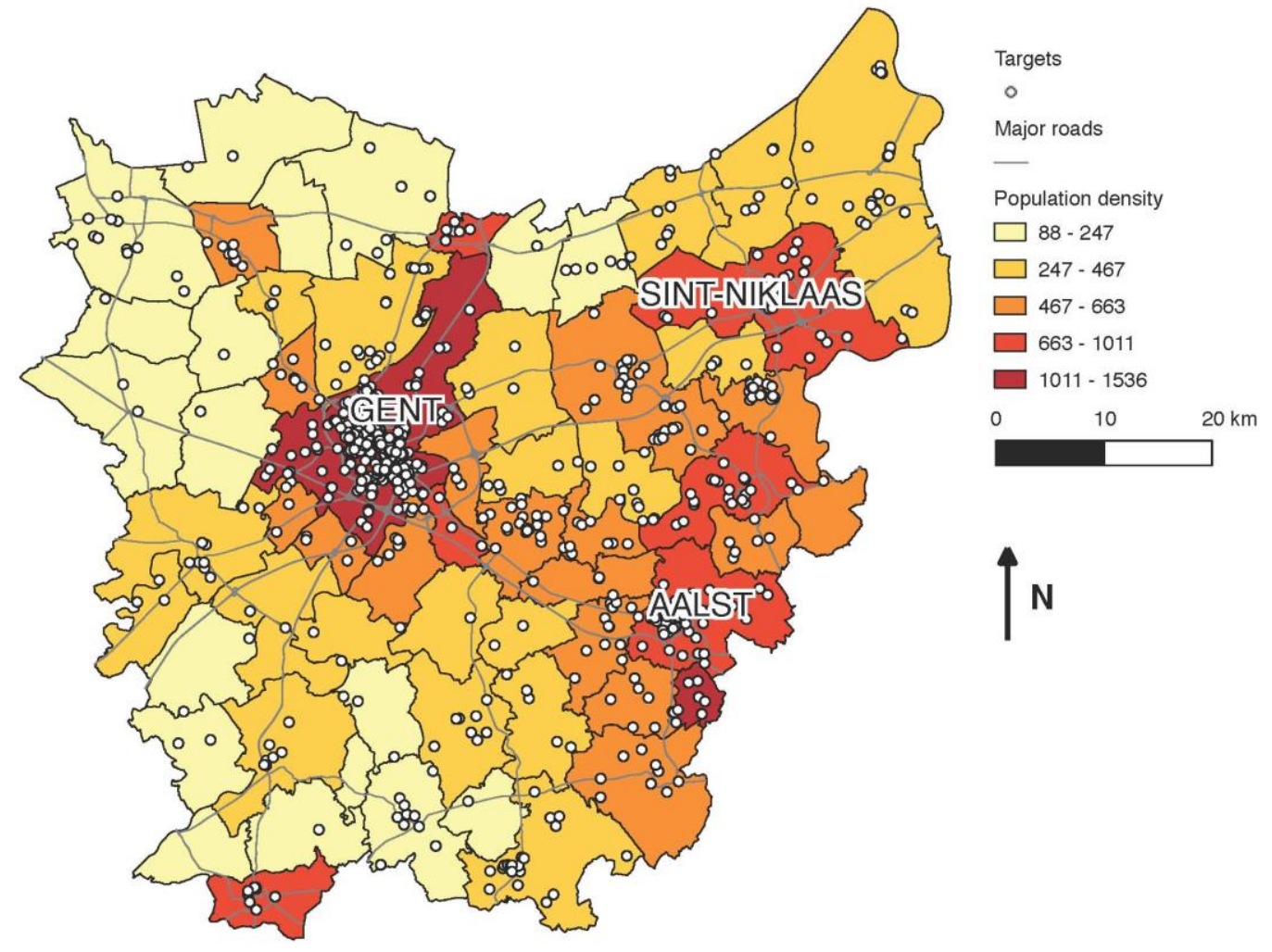

Figure 1 East Flanders (Belgium) map of study area with municipalities color-coded for population density (cities with a population of $50,000+$ inhabitants are labeled) and locations of burglary targets

Recorded crime data for all aggravated burglaries committed between 2006 and 2012 in East Flanders and for which at least one offender is known were acquired from the Belgian Federal Police. 4,308 aggravated burglary cases committed by 4,089 unique burglars, equivalent to 7,379 burglarburglary pairs or crime trips, were extracted from the Belgian General Police Database. This police database is the main source for nationwide crime statistics in Belgium and contains information on offenders, such as their date of birth and gender, and offences, such as the location of the offence and time window of the event.

In order to be included in the current analysis, the burglaries had to match several additional selection criteria that are similar to the selection criteria adopted in previous applications of the discrete spatial choice method to studying offence location choice (e.g., Bernasco, et al., 2012; Bernasco \& Nieuwbeerta, 2005). These criteria and their impact on the sample size are summarized in Fout! Verwijzingsbron niet gevonden.. First, only burglaries committed by an offender with a legal address in East Flanders at the time of the offence were retained. This was primarily done for theoretical reasons. While it is plausible that offenders residing inside East Flanders consider only targets in the study area, this is highly unlikely for offenders residing outside the study area. The latter are more likely to select targets from a different choice set. Second, the address information for both the crime site and the offender's legal residence had to be geocodable unambiguously with address-level accuracy. Third, only burglaries involving a single offender were included. All burglaries that involved multiple offenders were excluded from the analysis to avoid the need to study the complex web of interactions between co-offenders. With regard to burglary, co-offending introduces complexity in terms of deciding on the correct starting point of the crime trip and brings additional 
choice situations into the equation (Bernasco \& Nieuwbeerta, 2005, p. 8), such as whether offenders first select a co-offender and then a target or vice versa. Moreover, Bernasco (2006) previously demonstrated that co-offending burglars and burglars operating individually rely on similar environmental characteristics when selecting a burglary target. Fourth, because the Belgian Land Registry data did not contain information on apartment buildings, we were forced to ignore all burglaries that took place in an apartment building. In other words, only burglaries committed in residential houses in East Flanders were included in the analysis. Finally, for burglars that committed multiple burglaries, one burglary case was randomly selected and included in the final analysis. All other cases were disregarded. In addition to providing a clearer test of the model, this strategy also accounts for statistical dependency in the data.. Burglars committing multiple burglaries are an example of a nested data structure that may lead to artificially small standard errors and spuriously significant results. Previously, discrete spatial choice models of crime target selection accounted for nested data structures by estimating robust standard errors or Huber Sandwich estimators (e.g., Bernasco, 2010b; Bernasco, et al., 2012; Bernasco \& Kooistra, 2010; Summers, 2012; Townsley, et al., 2014). However, this may not necessarily be an appropriate strategy for maximum likelihood estimated non-linear models such as the conditional logit model since the assumption that the obtained estimators of a miss-specified model - which is implicitly acknowledged by computing robust standard errors - are consistent and unbiased does not hold (Freedman, 2006). Because of the risk of obtaining inconsistent and biased estimators and the fact that it is insensible to correct standard errors of inconsistent parameters, it was decided to reduce nests as much as possible and randomly select one burglary for each burglar that was involved in multiple burglaries.

In total, 650 unique burglars and their burglaries were included in the analysis. Burglars were on average 31.21 years old (standard deviation [S.D.] = 12.11). The youngest burglar was 14 years old, the oldest 72 years old. The majority of burglars were male $(85.18 \% ; \mathrm{N}=546)$ and had not been previously associated with a cleared aggravated burglary $(53.69 \% ; \mathrm{N}=349$ ). Focusing on the Euclidean distance from the offender's home ${ }^{2}$ to their crime site, the so-called journey-to-crime or crime trip distance, we find that burglars travelled on average $6.17 \mathrm{~km}$ (S.D. $=8.47$ ) before committing their offence. ${ }^{3}$ The furthest burglary target was located at $49.65 \mathrm{~km}$ from the offender's

\footnotetext{
${ }^{2}$ Although it is common to assume that the offender's home is the relevant reference point for computing distance measures in offender spatial decision-making studies (Baudains, Braithwaite, \& Johnson, 2013; Bernasco \& Block, 2009; Bernasco, et al., 2015; S. D. Johnson \& Summers, 2015; Townsley, et al., 2014), this assumption does not stand unchallenged. In fact, research suggests that offenders may begin their crime journeys from a variety of locations including a partner's home or a leisure location (Van Daele, 2009; Wiles \& Costello, 2000, p. 40). Nevertheless, a number of theoretical and practical arguments warrant this assumption such as the importance of the offender's home for his use and awareness of the environment (Canter \& Larkin, 1993; Sarangi \& Youngs, 2006) and the typical lack of reliable address information on other reference points in police recorded crime data (Bruinsma, 2007, p. 485).

${ }^{3}$ While the Euclidean distance may not be the economically relevant cost, it is considered to be the most optimal distance measure available (Kent, Leitner, \& Curtis, 2006) and best-suited for the layout of European cities (Smith, Bond, \& Townsley, 2009). Furthermore, we computed Pearson correlation coefficients for a random sample of 1,000 offender-target pairs between the Euclidean distance measure, the shortest travel path (the shortest distance between the offender's home and the target) and the temporally optimized distance measure (the quickest route between the offender's home and the target). These correlations demonstrate a near perfect positive association between the straight-line distance measure and the shortest travel path distance measure $(r=0.996 ; p<0.001)$ as well as between the straight-line and temporally optimized distance measure $(r=0.950 ; p<0.001)$, supporting our assertion that they can be used interchangeably.
} 
home. This more or less corresponds with an offender living at one end of the study area committing a burglary at the other end. The distribution of crime trip distances is displayed in Fout! Verwijzingsbron niet gevonden.. As the number of available targets increases with distance, the empirical distance-decay function should be normalized against the target distribution for a full understanding. For that reason, we subsequently plot: the empirically observed crime trip distribution (plot $A$ in Figure 2), a distribution of 10,000 random crime trips for each of the 650 offenders (plot B in Figure 2), and the normalized crime trip distribution (plot C in Figure 2), showing even stronger distance decay than suggested by the empirical, non-normalized distribution.

Table 1 Selection of burglary cases

\begin{tabular}{lcc}
\hline \multicolumn{1}{c}{ Selection criterion } & Burglaries & Burglars \\
\hline $\begin{array}{l}\text { Cleared aggravated burglaries in recorded } \\
\text { crime data committed in East Flanders } \\
\text { Involving at least one offender residing in }\end{array}$ & 4,308 & 4,089 \\
$\begin{array}{l}\text { East Flanders } \\
\text { For which legal address information could }\end{array}$ & 2,271 & 2,117 \\
be unambiguously geocoded with address- & & \\
level accuracy & 1,939 & 1,839 \\
Committed by a single offender & & 923 \\
Not committed in an apartment building & 1,156 & 650 \\
One burglary per unique burglar & 801 & 650 \\
\hline
\end{tabular}



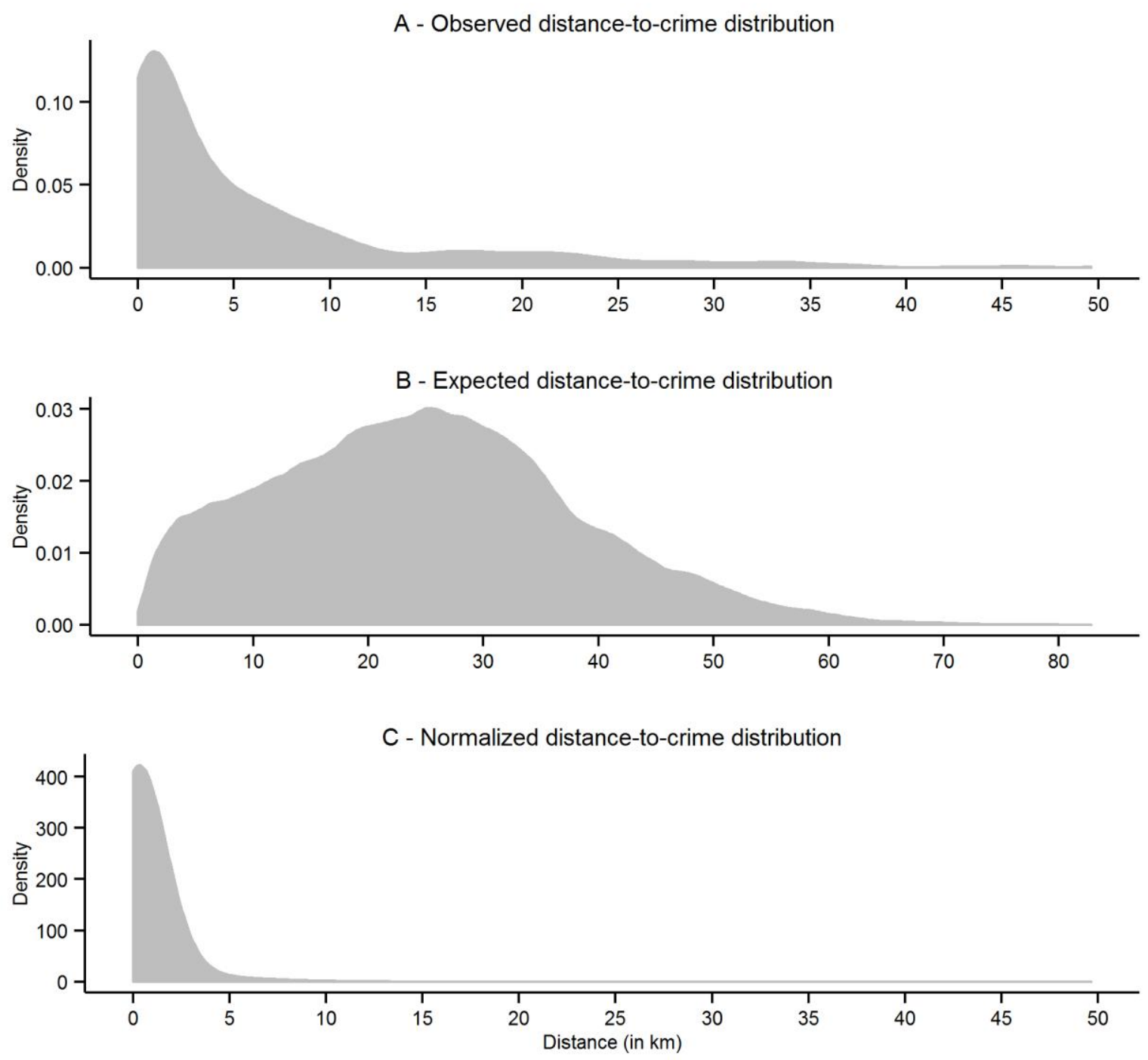

Figure 2 Kernel density plot of observed distance-to-crime distribution (plot A). Kernel density plot of expected distanceto-crime distribution (plot B). Kernel density plot of observed distance-to-crime distribution normalized against the distribution of targets (plot C).

\subsection{Residential housing data}

Information on attributes of residential properties in East Flanders was obtained through the Belgian Land Registry. In this Registry, for a land plot corresponding with a house, the accompanying information can be extracted straightforwardly from the database. We obtained information on 503,950 residential housing plots. Four plots were removed from the database because they were built with multiple dwellings and we could not unambiguously identify the correct house associated with the land plot. 359 plots were additionally removed because of coding errors in the database. In total, 503,589 residential properties were included in the final choice set.

The Belgian Land Registry data reflects the situation on 1 January 2013 and contains the construction type of a house, the number of floors in addition to the ground floor, whether there is a rooftop living floor, whether a house has a garage, availability of central heating and/or air-conditioning 
system, and the built surface area (in 1,000 $\mathrm{m}^{2}$ ). All variables have been included in our analysis. Table 2 provides descriptive statistics for all house-level attributes. ${ }^{4}$ In addition to the variables available in the Registry data, we computed the Euclidean distance between all alternatives included in the final choice set and each of the 650 offenders' residences.

Perceived reward is measured using the built surface area and whether a garage is present (cf. Cromwell, et al., 1991; Nee \& Taylor, 2000). The central heating and air-conditioning variable is an indicator for perceived rewards as well as the potential effort required to access the target (Cromwell, et al., 1991, p. 27; Wright, et al., 1995, p. 49). We treat this variable as a proxy measure for the quality of the construction and assume that houses without central heating are likely older and might be less well maintained. As a result, they are probably easier to access and, coincidentally, may offer smaller rewards. Distance from the offender's home to the alternative is an indicator for perceived effort (Townsley, et al., 2014). The construction type is an indicator for potential effort as well as risk (cf. Bennett \& Wright, 1984; Taylor \& Nee, 1988): it is more difficult to gain access to the back of terraced houses and burglars might have an increased risk of detection in comparison to semi-detached and detached houses. The number of floors and the presence of a rooftop living floor are risk indicators. Houses with multiple floors have fewer escape routes than houses with just a ground floor (Beavon, Brantingham, \& Brantingham, 1994, p. 130; Bennett \& Wright, 1984, p. 65): all ground floor windows can be used relatively safely as exits, while burglars might get cornered on the floors above the ground if the residents return home or could injure themselves when using an above ground floor window as an exit. The same reasoning holds for a rooftop living floor.

Table 2 Descriptive statistics for house-level variables

\begin{tabular}{|c|c|c|c|c|c|}
\hline & & \multicolumn{2}{|c|}{$\%$} & \multicolumn{2}{|c|}{$\mathbf{N}$} \\
\hline & Terraced & & & & \\
\hline \multirow[t]{2}{*}{ Construction type } & Semi-detached & & & & \\
\hline & Detached & & & & \\
\hline \multirow[t]{2}{*}{ Number of floors } & Ground floor & & & & \\
\hline & One or more & & & & \\
\hline \multirow{2}{*}{ Rooftop living floor } & No & & & & \\
\hline & Yes & & & & \\
\hline \multirow{2}{*}{ Garage present } & No & & & & \\
\hline & Yes & & & & \\
\hline \multirow{2}{*}{ Central heating/AC } & No & & & & \\
\hline & Yes & & & & \\
\hline \multirow{2}{*}{\multicolumn{2}{|c|}{ Built surface area $\left(1,000 \mathrm{~m}^{2}\right)$}} & Mean & S.D. & Min. & Max. \\
\hline & & 0.136 & 0.335 & 0 & 97.080 \\
\hline
\end{tabular}

\section{Method}

\subsection{Discrete spatial choice modeling and the conditional logit model}

A discrete spatial choice approach is used to study burglars' target selection process (Bernasco, et al., 2015; Bernasco \& Ruiter, 2014). This approach applies the discrete choice framework to a spatially referenced choice setting such as burglars selecting a house to burglarize. It expands the general

\footnotetext{
${ }^{4}$ The built surface area variable contains a number of extremely small and large values. Looking up the associated land plots and houses on Google Maps and Google Street View (Vandeviver, 2014) revealed that the smallest values correspond to very small houses built on small land plots. The largest values were found to be associated with land plots built with (large) houses and one or more barns, greenhouses or warehouses.
} 
framework by estimating the effect of environment-specific features on a decision-makers' choice (Bernasco \& Nieuwbeerta, 2005). With regard to burglary, this permits including house-specific attributes such as construction type and surface area, and the distance from the alternative to the offender's residence. This approach identifies the influence of environmental features on burglars' target choice.

The approach is rooted in the micro-economic theory of random utility maximization (RUM) (McFadden, 1974) and enables studying the choice behavior of decision-makers selecting one alternative from a larger set of exhaustive and mutually exclusive alternatives. RUM-theory assumes that individuals are rational in their choice behavior and will select the alternative that is expected to maximize their perceived utility. Under this assumption, the discrete spatial choice approach can be estimated using a conditional logit model (Bernasco \& Nieuwbeerta, 2005).

The discrete spatial choice approach has previously been applied to study burglary location choice (e.g., Bernasco \& Nieuwbeerta, 2005), robbery target selection (e.g., Bernasco \& Block, 2009), violent offenders' spatial behavior (e.g., Summers, 2012), rioters' target choices (e.g., Baudains, et al., 2013) and theft from motor vehicles (e.g., S. D. Johnson \& Summers, 2015). It is currently considered to be the customary approach to study offenders' target selection processes since it combines all theoretically important features of the target selection process in a single framework (Townsley, et al., 2014): burglars, their selected targets, all houses from which they can choose and the criteria that affect their choice.

\subsection{Sampling-of-alternatives procedure}

Estimating a conditional logit model involves an iterative maximum likelihood process and requires the likelihood function to be computed for each decision-maker-by-alternative combination (BenAkiva \& Lerman, 1985). For the current paper, this would be practically infeasible since at least $327,332,850$ decision-maker-by-alternative combinations are involved in estimating the models. ${ }^{5}$ Moreover, the model requires access to all choice-specific characteristics additionally burdening the computational process.

Since McFadden (1978a) demonstrated that these models can be consistently estimated on a subset of alternatives provided that the chosen alternative is included and for each choice at least one alternative from the choice set is randomly sampled as well, we randomly sampled a subset of alternatives that was one-eighth the size of the original choice set (Nerella \& Bhat, 2004) and repeated this procedure for each chosen alternative. In the end, 40,916,200 decision-maker-byalternative combinations have been included in the estimation process. ${ }^{6}$ Previously, this strategy was successfully applied to study crime location choice processes when confronted with large choice sets (e.g., Bernasco, 2010a; Bernasco, et al., 2012).

Given the recurring finding of distance decay in burglary behavior, it is intuitively appealing to apply importance sampling throughout the sampling-of-alternatives procedure. However, favoring nearby alternatives over faraway alternatives does not result in a more efficient model estimation procedure (Ben-Akiva \& Lerman, 1985, p. 265). The sampling-of-alternatives procedure was therefore performed using simple random sampling.

\footnotetext{
${ }^{5}$ Each of the 650 burglars can choose one house from a choice set of 503,589 residences (alternatives).

${ }^{6} 650$ burglars multiplied by a random subset of 62,948 alternatives (this includes the chosen alternative).
} 
Even after applying the sampling-of-alternatives procedure, the size of the decision-maker-byalternatives dataset as well as the size of buffer memory required to store intermediary estimation results exceeds the limits of most contemporary desktops. The Ghent University High Performance Computing infrastructure was therefore used to estimate all models. In particular, we ran $\mathrm{R}$ version 3.0.2 with ICTCE 5.5.0 on two linked dual socket Intel Xeon X5675 hexacore nodes with 96GB of physical memory.

\subsection{Bootstrapping procedure}

To correct for possible sampling bias introduced by the sampling-of-alternatives procedure and to demonstrate the robustness of our parameter estimates, we have implemented a bootstrapping procedure that re-estimated the conditional logit model 20 times. Each iteration of this procedure was performed with a different random sample of 650 burglary cases (out of a total of 801 possible burglaries) and for each included burglary a different random sample of 62,947 non-selected houses was drawn from the full choice set. This bootstrapping procedure is very similar to the one implemented by Bernasco, et al. (2012) for their analysis of robbery target choice in Chicago.

By following this bootstrapping procedure, more accurate estimates of the parameter coefficients and more conservative estimates of their standard errors can be obtained since this procedure results in an additional (between-iteration) variance. In total, this procedure yields 20 sets of model results. A single set of overall (bootstrapped) parameter estimates and associated standard errors is obtained by combining the 20 sets of results according to the procedure for combining bootstrapped regression coefficients and standard errors explained by Rubin (1987). An overall parameter coefficient is obtained by averaging the coefficient across all sets of results and for each coefficient an overall standard error is computed by taking the square root of the sum of the within- and between-iteration variances.

\section{Research hypotheses}

Based on the previously outlined theoretical framework, three general hypotheses were already articulated. We now link these hypotheses with the available residential property variables. First, higher perceived rewards are hypothesized to increase the likelihood that a house is burglarized. In particular, we hypothesize that the likelihood that a house is burglarized increases with its built surface area. Moreover, we hypothesize that houses with a garage have a greater likelihood of being burglarized than houses without any garages.

Second, lower perceived effort is hypothesized to increase the likelihood that a house is targeted. Although the absence of central heating and/or air-conditioning may signal lower rewards, it could also indicate that it is easier to gain entrance to a house. We therefore expect that houses with central heating have a smaller likelihood of being burglarized than houses without central heating. Moreover, the likelihood of being burglarized decreases as houses are located further away from the offender's home.

Third, lower perceived risk is hypothesized to increase the likelihood that a house is burglarized. Terraced houses are hypothesized to have a smaller likelihood of being burglarized than semidetached and detached houses. In addition, we hypothesize that houses with one or more floors and 
a rooftop living floor have a smaller likelihood of being burglarized than houses with just a ground floor and without a rooftop living floor respectively.

\section{Results}

The estimation results of the bootstrapped conditional logit models are summarized in Table 3 . This table presents overall parameter coefficients, overall standard errors and overall odds ratios (ORs). A selection of model fit statistics is also provided. The ORs describe the amount the odds of a house being selected increase multiplicatively with a one-unit change in the associated independent variable. To help with the interpretation of the model, Figure 3 plots the estimated overall odds ratios and their associated confidence intervals on a log scale. The dots represent the estimated odds ratios. Dots on the left of the dashed vertical line represent a decrease in the likelihood of a house being targeted for burglary, while dots on the right side of that reference line denote an increase in the probability of target selection. The horizontal lines represent the $95 \%$ confidence intervals associated with the estimated odds ratios. A line intersecting the dotted line indicates that the effect of the associated parameter is not statistically significant at $p<0.025$ (two-sided).

With respect to overall model fit, pseudo $R^{2}$ values associated with conditional logit models are expected to be considerably smaller than $R^{2}$ values typically observed in the context of ordinary least squares regression models. Values between 0.2 to 0.4 indicate excellent model fit (McFadden, 1978b, p. 307). The current model's observed pseudo $R^{2}$ measure of 0.15 suggests an acceptable fit to the data.

Focusing on the target attributes, three out of six house attributes are significantly related with the likelihood of target selection. Houses have a smaller likelihood of being burglarized if they are semidetached, have a garage and are outfitted with a central heating and/or air-conditioning system. The overall effect of construction type is significant (likelihood ratio test statistic $=8.714 ; \Delta \mathrm{df}=2 ; p=$ 0.013) and the partial effect of semi-detached suggests that burglars prefer terraced houses over semi-detached houses. All other things being equal, the odds of a semi-detached house being burglarized is 28 percent smaller than the odds for a terraced house. Similarly, the odds of a house with a garage being burglarized are 20 percent smaller than those of a house without a garage. Somewhat surprisingly, residences without a garage are more likely to be targeted by burglars than houses that have a garage. Moreover, the odds of a house being burglarized are 32 percent smaller if it is outfitted with a central heating or air-conditioning system compared to houses that are not outfitted with similar systems. In other words, offenders display a preference for burglarizing houses that have no central heating and/or air-conditioning system installed. However, a number of house attributes are not significantly associated with the probability of a house being targeted for burglary. The number of floors, the presence of a rooftop living floor and the built surface area all exhibit no statistical significant effects suggesting that burglars may not rely on these target attributes to distinguish between houses.

Finally, as profusely demonstrated in the offender spatial decision-making literature, offenders shy away from burglarizing houses that are located further away from their home. Instead, they have a preference for targeting houses that are close by their home. The estimated OR of 0.79 for distance is significant and implies that, ceteris paribus, the odds of a house being selected decrease by 21 percent for every kilometer it is further away from the offender's home. In other words, remote houses are less likely to be targeted. 
Table 3 Discrete spatial choice model of burglars' choice of target house in East Flanders. Maximum likelihood estimates from 20 bootstrapped conditional logit models with random sampling of 650 burglaries from 801 burglary cases and for each burglary case random sampling of 62,947 alternatives from 503,589 houses.

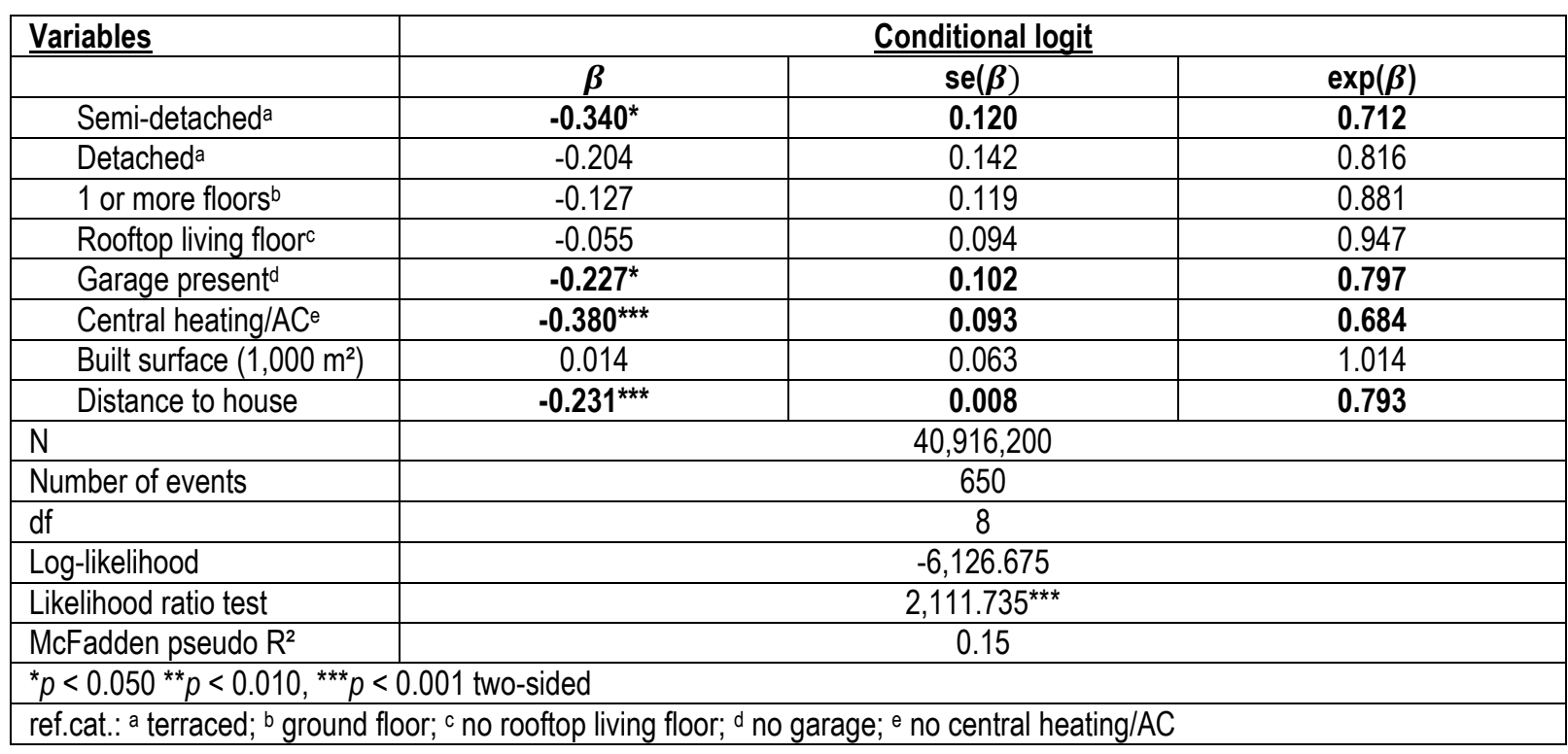




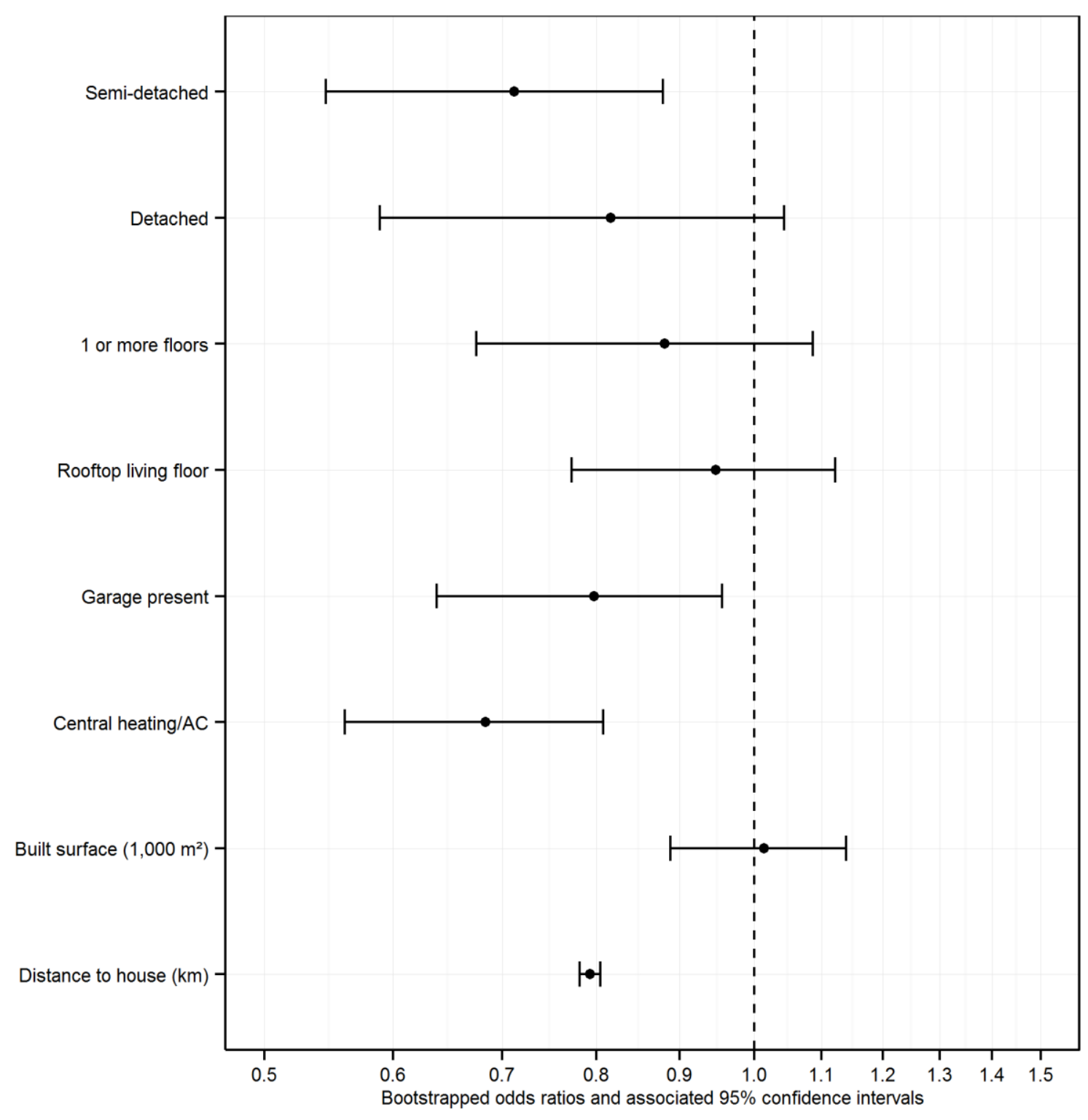

Figure 3 Forest plot of odds ratios and associated $95 \%$ confidence intervals for combined bootstrapped conditional logit model results of burglars' choice of target house in East Flanders. Note: the x-axis is on a log scale.

\section{Conclusion and discussion}

This study sought to answer which house attributes influence burglars' decision when selecting a target. The rational choice perspective asserted that environmental characteristics related to the target allow burglars to select houses by optimizing a combination of perceived rewards, efforts and risks. Burglars were expected to look for more rewarding targets, targets that require minimal effort to reach or enter as well as less risky targets. A discrete spatial choice framework was applied to study burglars' target selection process in a Belgian province. The key advantage of our study is that this process was modeled for the first time at its ultimate outcome; that is, the house that is eventually burglarized. This allowed us to combine the insights from earlier ethnographic research, offender interviews and experiments with the power of the discrete spatial choice approach.

\subsection{Which house attributes affect burglars' target choice?}


Initially, we sought to determine which house attributes affected burglars' decision to target a house. Our results indicate that burglars primarily distinguish between targets by relying on effort-related attributes. This confirms our second hypothesis that lower perceived efforts increase the likelihood that a house is burglarized. We could not confirm our first hypothesis related to reward nor did we find confirmation for our third hypothesis related to risk.

First, burglars were expected to look for profitable targets. Although higher perceived rewards were hypothesized to increase the likelihood that a house is selected for burglary, our results do not confirm this. In contrast with the first hypothesis, we found that the likelihood of a house being burglarized actually decreased with higher perceived rewards as indicated by the presence of a garage at or nearby the house (cf. Cromwell, et al., 1991, p. 49). Moreover, when controlling for other house attributes the size of the house, another reward-related attribute, did not increase nor decrease the odds of a burglar selecting a house for a burglary. These results challenge earlier findings from burglar accounts and experiments that demonstrated that offenders discriminate between targets based on reward-related house attributes such as the size of the house, general upkeep and the type of car parked outside (Bennett \& Wright, 1984; Nee \& Meenaghan, 2006; Nee \& Taylor, 1988, 2000; Taylor \& Nee, 1988; Wright \& Logie, 1988). Instead, our results mimic those of Wright, et al. (1995, p. 49) who found that affluence-related attributes at the house-level had little impact on burglars' decision to burglarize a particular house. In fact, our results reflect the suggestion that burglars do not necessarily need to rely on an appraisal of the target's affluence as they may expect to make a profit anyway because of the large-scale availability of profitable loot such as smartphones, tablets and jewelry in today's households (Townsley, et al., 2014, p. 20; Vandeviver, Van Daele, \& Vander Beken, 2015, p. 15).

Second, we expected burglars to make minimal effort to achieve their goal and that this would be reflected in their choice of target. Our results confirm the second hypothesis that stated that lower perceived efforts increase the likelihood of a house being burglarized. Burglars' appreciation of the effort required to commit an offence was based on the distance to their home address and the effort required to gain entrance to a house as indicated by the availability of central heating and/or airconditioning. The likelihood of a house being burglarized decreased with the distance to the offender's home. This comes as no surprise, since it has been elaborately reported in previous studies that burglars prefer nearby targets (cf. inter alia Gabor \& Gottheil, 1984; Turner, 1969; Wiles \& Costello, 2000). Interestingly, burglars favor houses without central heating and/or airconditioning: houses that have no central heating and/or air-conditioning system had a greater odds of being selected for burglary than houses that have a central heating system installed. Although we do not argue that the presence of a central heating system makes a house vulnerable for burglary, we reason that the absence of a central heating and/or air-conditioning system indicates that less effort is required to gain access to the house because houses without such systems will typically be older and the doors and windows could be poorly maintained or made of inferior materials. Houses without central heating may also offer smaller rewards. The current results do not stand alone and corroborate those from ethnographic studies that found burglars opt for dwellings that can be easily broken into because of weathered doors or window frames (Cromwell, et al., 1991; Shaw \& Gifford, 1994; Wright, et al., 1995). However, they challenge those of earlier studies that identified the presence of air-conditioning systems as a cue that might signal an attractive target (Wright, et al., 1995, p. 49) and found some burglars to look for houses outfitted with air-conditioning systems because these can be manipulated to gain entrance to the building (Cromwell, et al., 1991, p. 27). 
Third, lower perceived risk was hypothesized to increase the likelihood of a residence being burglarized. However, no support was found for this hypothesis. Construction type affected burglars' location choice. Contrary to our hypothesis, however, terraced houses had a greater likelihood of being burglarized than semi-detached houses. Moreover, our results suggest that burglars do not distinguish between terraced and detached houses. This contrasts with a number of studies that found terraced houses to be less prone to burglary (Bennett \& Wright, 1984; Hakim, Rengert, \& Shachmurove, 2001; Maguire \& Bennett, 1982; Wright \& Logie, 1988). Our contrasting finding is perhaps rooted in the design of a number of earlier studies that relied on stated preferences to study burglars' target selection process. Previous studies predominantly relied on offenders' personal accounts to gain insight in burglars' motives for selecting a particular house to burglarize (e.g., Bennett \& Wright, 1984; Cromwell, et al., 1991), even though it might not be wholly appropriate to rely on verbal reports when studying the motivations and intentions that underlie offenders' decisions and behavior. Cognitive psychological research suggests that individuals rarely have an accurate, conscious understanding of the complex cognitive processes that underlie their choices (Kahneman, 2011, pp. 85-88; Nisbett \& Wilson, 1977). They may be unaware of factors that have a major influence on their decisions or recall idiosyncratic events instead of their general reasoning and behavior. Particularly for burglars, they may be unwilling to say what they would do if the situation was real. By adopting a revealed preferences approach (Bernasco, 2010a; Rushton, 1969) and examining the factors that are associated with the behavioral outcomes of decision-making and thought processes, it is possible to gain insight into the underlying choices. In other words, our results indicate that although offenders say they shy away from burglarizing terraced houses, when push comes to shove they are not hindered by their apparent dislike for terraced houses. Furthermore, we could not establish whether other risk-related attributes such as the number of floors and the presence of a rooftop living floor increased or decreased the likelihood of a house being burglarized. Apparently, when all other house attributes are controlled for burglars do not scrutinize individual dwellings for risk-related attributes to appraise the risk of burglarizing a particular house. In other words, burglars have no specific preference for less risky dwellings.

\subsection{Limitations}

This study has several potential limitations. First, findings rely on recorded crime data and may be subject to selection effects. In particular, local burglars may be overrepresented in the recorded crime data (Bruinsma, 2007; Rengert, 2004) resulting in an underestimation of burglar mobility and the number of remote targets being burglarized. While undesirable, its problematic character should not be overstated. Alternative methodologies suffer from similar biases. As highlighted, results from offender interviews may suffer from a number of cognitive biases including availability heuristics and conjunction fallacies (Kahneman, 2011) and ethnographic studies tend to focus on prolific offenders (Townsley, et al., 2014).

Second, like other offender spatial-decision making studies, this study assumed that the offender's home is the starting point of their crime trip and ignored that crime journeys could be undertaken from various locations (see for example Van Daele, 2009; Wiles \& Costello, 2000, p. 40). However, using the home as the starting point of a crime trip has theoretical grounding since the location of the home is of primary importance for an offender's use and understanding of the surrounding environment (Canter \& Larkin, 1993; Sarangi \& Youngs, 2006) and it imposes an important constraint on the area in which offenders look for suitable targets since at some point in time an offender will 
have to return home (Rengert, 2004). Furthermore, our research was based on police files. These data commonly lack information on additional reference points or the actual location from which the offender left to commit his offense (Bruinsma, 2007, p. 485). Address information in police recorded crime data is typically limited to the registered, official address. As a result, we could not scrutinize the importance of other reference points for an offender's spatial decision-making process.

Third, analyses are limited to burglaries committed in houses since the Registry data did not include information on apartments. Although this limits the scope of our study, offender accounts suggest burglars may bypass apartments altogether (Bennett \& Wright, 1984, pp. 65-66). In addition, burglaries in apartments make up only a small proportion of all domestic burglaries in Belgium. Approximately $80 \%$ of all burglaries in Belgium are committed in houses..

\subsection{Future research}

To conclude, several avenues of future research are outlined. First, the null results for a number of house variables included in our analysis merit discussion and continued research. On the one hand, these variables may be good indicators of rewards, efforts and risks. They may be sufficiently discriminating and thus allow us to reject the proposed hypotheses. For instance, the lack of effect of built surface area on the probability of target selection is surprising but could indicate that offenders are not concerned with seeking higher rewards. As already outlined, they may expect to make a profit anyway and do not feel compelled to distinguish between targets based on reward-related house attributes. On the other hand, these variables could simply be poor proxies for the concepts they purport to measure. In that case, the lack of effect of built surface area may indicate that larger homes do not yield higher rewards. Larger homes are just what they are: large homes, but they are not necessarily rich pickings. However, it could also be that burglars are unable to (accurately) assess the built surface area of a property. When selecting a target, burglars make a flurry of decisions in just a moment's time. With regard to the built surface area, we hypothesized that one of these decisions relate to an assessment of the size of the property. Yet, the information feeding this decision will typically be limited to a quick glance of the property's façade. While a dwelling with a small façade may be small in terms of built surface area, it may be considerably larger in terms of the living area and could be a rewarding target to burglarize. Nevertheless, to rule out any of these explanations and improve our understanding of burglary target selection requires a continued search for accurate and detailed fine-grained spatial information. This study was a first step and demonstrated that the analytical framework offered by the discrete spatial choice approach can be applied to a very fine-grained spatial resolution. Future research may continue to invest in this branch of research and could continue exploring what house-level data is available in their country to improve or rebuke the conclusions from this study. The land register or tax service may be one source for information on properties. Insurance companies may be another source for finding detailed house attributes. When providing insurance coverage for fire or burglary, insurance companies require homeowners to provide them with detailed information on their property which could be analyzed in future research.

Second, like previous crime location choice studies this study did not explicitly acknowledge that offender's consideration with regard to crime site selection apply to multiple levels of spatial aggregation. Crime site selection is a spatially structured hierarchical decision-making process (Bernasco \& Nieuwbeerta, 2005; Brantingham \& Brantingham, 1984; Cornish \& Clarke, 1986a) that 
entails that burglars initially distinguish between larger areas such as a municipality or equivalent area before narrowing down their choice and eventually selecting a dwelling to burglarize. This implies that environmental attributes at multiple levels of spatial aggregation affect burglars' choice of crime site. Burglars have a choice among all available houses in a given area. Houses are grouped in streets, which in turn are grouped in neighborhoods and municipalities. Dwellings in the same municipality share unobserved attributes such as the number of active burglars in the area. Residential properties in the same street share similar unobserved attributes such as the amount of traffic. This introduces dependency between nested choices and burglars' location choice problems might better be defined by the house, street, neighborhood and municipality that is selected. Testing such models involves applying a variation of the nested logit model (Ben-Akiva \& Lerman, 1985; Train, 2009). Furthermore, a similar analysis could be extended in depth by including additional house attributes and more nuanced environmental attributes of various levels of spatial aggregation. For instance, the location of a house on a street segment and whether it is observable from the surrounding residences is believed to affect burglars' target choice (Bennett \& Wright, 1984; Cromwell, et al., 1991; Taylor \& Nee, 1988). Street characteristics could be included as well since attributes such as connectedness and permeability are believed to affect burglary decisions (Beavon, et al., 1994; Townsley, et al., 2014).

Finally, future applications could study burglars' cost and benefit balancing process in detail by investigating the presence of interaction effects between attributes of reward, effort and risk. The current study was limited to establishing what residence-level attributes affect burglars target choices, but certain environmental attributes could moderate the effects of other attributes on burglars' crime site choice. Investigating these might shed light on how burglars hope to compensate reduced rewards or why certain risky targets are selected.

\section{Acknowledgements}

The computational resources (STEVIN Supercomputer Infrastructure) and services used in this work were kindly provided by Ghent University, the Flemish Supercomputer Center (VSC), the Hercules Foundation and the Flemish Government - department EWI.

Part of this research was carried out while the first author was visiting the Netherlands Institute for the Study of Crime and Law Enforcement (NSCR) in Amsterdam, the Netherlands.

We thank Wim Bernasco for the many insightful discussions and practical tips that helped us to realize this article. We thank Jeff Brantingham for comments on an earlier draft of this article. Finally, we thank the editor Jay Gatrell and the two anonymous reviewers for their helpful feedback on a previous version.

\section{References}

Andresen, M. A., \& Malleson, N. (2011). Testing the Stability of Crime Patterns: Implications for Theory and Policy. Journal of Research in Crime and Delinquency, 48 (1), 58-82.

Andresen, M. A., \& Malleson, N. (2013). Crime seasonality and its variations across space. Applied Geography, $43(0), 25-35$.

Baudains, P., Braithwaite, A., \& Johnson, S. D. (2013). Target Choice During Extreme Events: A Discrete Spatial Choice Model Of The 2011 London Riots. Criminology, 51 (2), 251-285. 
Beavon, D. J. K., Brantingham, P. L., \& Brantingham, P. J. (1994). The Influence of Street Networks on the Patterning of Propery Offenses. In R. V. Clarke (Ed.), Crime Prevention Studies (pp. 115148). Willow Tree Press, Monsey, N.Y.

Ben-Akiva, M. E., \& Lerman, S. R. (1985). Discrete Choice Analysis: Theory and Application to Travel Demand. MIT Press, Cambridge, Massachusetts.

Bennett, T., \& Wright, R. (1984). Burglars on Burglary. Gower, Aldershot.

Bernasco, W. (2006). Co-offending and the Choice of Target Areas in Burglary. Journal of Investigative Psychology and Offender Profiling, 3 (3), 139-155.

Bernasco, W. (2010a). Modeling Micro-Level Crime Location Choice: Application of the Discrete Choice Framework to Crime at Places. Journal of Quantitative Criminology, 26 (1), 113-138.

Bernasco, W. (2010b). A Sentimental Journey to Crime: Effects of Residential History on Crime Location Choice. Criminology, 48 (2), 389-416.

Bernasco, W., \& Block, R. (2009). Where Offenders Choose to Attack: a Discrete Choice Model of Robberies in Chicago. Criminology, 47 (1), 93-130.

Bernasco, W., Block, R., \& Ruiter, S. (2012). Go where the money is: modeling street robbers' location choices. Journal of Economic Geography, 13 (1), 119-143.

Bernasco, W., Johnson, S. D., \& Ruiter, S. (2015). Learning where to offend: Effects of past on future burglary locations. Applied Geography, 60 (0), 120-129.

Bernasco, W., \& Kooistra, T. (2010). Effects of Residential History on Commercial Robbers' Crime Location Choices. European Journal of Criminology, 7 (4), 251-265.

Bernasco, W., \& Nieuwbeerta, P. (2003). Hoe kiezen inbrekers een pleegbuurt? Een nieuwe benadering voor de studie van criminele doelwitselectie. Tijdschrift voor Criminologie, 45 (3), 254-270.

Bernasco, W., \& Nieuwbeerta, P. (2005). How Do Residential Burglars Select Target Areas? A New Approach to the Analysis of Criminal Location Choice. British Journal of Criminology, 45 (3), 296-315.

Bernasco, W., \& Ruiter, S. (2014). Crime Location Choice. In G. Bruinsma (Ed.), Encyclopedia of Criminology and Criminal Justice (pp. 691-699). Springer, New York.

Bottoms, A. E. (2007). Place, Space, Crime, and Disorder. In M. Maguire, R. Morgan \& R. Reiner (Eds.), The Oxford Handbook of Criminology (4th ed., pp. 528-574). Oxford University Press, Oxford.

Brantingham, P. J., \& Brantingham, P. L. (1984). Patterns in Crime. Macmillan, New York.

Breetzke, G. D. (2012). The effect of altitude and slope on the spatial patterning of burglary. Applied Geography, 34, 66-75.

Bruinsma, G. (2007). Urbanization and Urban Crime: Dutch Geographical and Environmental Research. In M. Tonry (Ed.), Crime and Justice in the Netherlands (Vol. 35, pp. 453-502). Chicago University Press, Chicago.

Canter, D., \& Larkin, P. (1993). The Environmental Range of Serial Rapists. Journal of Environmental Psychology, 13 (1), 63-69.

Clare, J., Fernandez, J., \& Morgan, F. (2009). Formal Evaluation of the Impact of Barriers and Connectors on Residential Burglars' Macro-Level Offending Location Choices. Australian and New Zealand Journal of Criminology, 42 (2), 132-158.

Cornish, D. B., \& Clarke, R. V. (1986a). Introduction. In D. B. Cornish \& R. V. Clarke (Eds.), The Reasoning Criminal: Rational Choice Perspectives on Offending (pp. 1-16). Springer-Verlag, New York.

Cornish, D. B., \& Clarke, R. V. (2006). The Rational Choice Perspective. In S. Henry \& M. M. Lanier (Eds.), The Essential Criminology Reader (pp. 18-29). Westview Press, Boulder, CO.

Cornish, D. B., \& Clarke, R. V. (1986b). The Reasoning Criminal: Rational Choice Perspectives on Offending. In A. Blumstein \& D. P. Farrington (Eds.), Research in Criminology (pp. 246). Springer-Verlag, New York.

Cromwell, P., Olson, J., \& Avary, D. A. W. (1991). Breaking and Entering: An Etnographic Analysis of Burglary. SAGE Publications Ltd., Newbury Park, CA. 
de Melo, S. N., Matias, L. F., \& Andresen, M. A. (2015). Crime concentrations and similarities in spatial crime patterns in a Brazilian context. Applied Geography, 62 (0), 314-324.

Elffers, H. (2004). Decision Models Underlying the Journey to Crime. In G. Bruinsma, H. Elffers \& J. De Keijser (Eds.), Punishment, Places and Perpetrators: Developments in Criminology and Criminal Justice Research (pp. 182-195). Willan Publishing, Cullompton.

Freedman, D. A. (2006). On the So-Called "Huber Sandwich Estimator" and "Robust Standard Errors". The American Statistician, 60 (4), 299-302.

Gabor, T., \& Gottheil, E. (1984). Offender Characteristics and Spatial Mobility - an Empirical Study and Some Policy Implications. Canadian Journal of Criminology-Revue Canadienne De Criminologie, 26 (3), 267-281.

Hakim, S., Rengert, G. F., \& Shachmurove, Y. (2001). Target search of burglars: A revised economic model. Papers in Regional Science, 80 (2), 121-137.

Johnson, D. (2013). The space/time behaviour of dwelling burglars: Finding near repeat patterns in serial offender data. Applied Geography, 41, 139-146.

Johnson, S. D., \& Summers, L. (2015). Testing Ecological Theories of Offender Spatial Decision Making Using a Discrete Choice Model. Crime \& Delinquency, 61 (3), 454-480.

Kahneman, D. (2011). Thinking, Fast and Slow. Penguin Books, London.

Kent, J., Leitner, M., \& Curtis, A. (2006). Evaluating the usefulness of functional distance measures when calibrating journey-to-crime distance decay functions. Computers Environment and Urban Systems, 30 (2), 181-200.

Maguire, M., \& Bennett, T. (1982). Burglary in a Dwelling: The Offence, the Offender and the Victim. Heinemann, London.

McFadden, D. (1974). Conditional Logit Analysis of Qualitative Choice Behavior. In P. Zarembka (Ed.), Frontiers in Econometrics (pp. 105-142). Academic Press, New York.

McFadden, D. (1978a). Modeling the choice of residential location. In A. Karlqvist, L. Lundqvist, F. Snickars \& J. W. Weibull (Eds.), Spatial Interaction Theory and Planning Models (pp. 75-96). North Holland, Amsterdam.

McFadden, D. (1978b). Quantitative Methods for Analyzing Travel Behaviour of Individuals: Some Recent Developments. In D. A. Hensher \& P. R. Stopher (Eds.), Behavioural travel modeling (pp. 279-318). Croom Helm London, London, UK.

Nee, C., \& Meenaghan, A. (2006). Expert Decision Making in Burglars. British Journal of Criminology, 46 (5), 935-949.

Nee, C., \& Taylor, M. (1988). Residential Burglary in the Republic of Ireland: A Situational Perspective. The Howard Journal of Criminal Justice, 27 (2), 105-116.

Nee, C., \& Taylor, M. (2000). Examining Burglars' Target Selection: Interview, Experiment or Ethnomethodology? Psychology Crime \& Law, 6 (1), 45-59.

Nerella, S., \& Bhat, C. R. (2004). Numerical analysis of effect of sampling of alternatives in discrete choice models. Travel Behavior and Values 2004, 1894 (1894), 11-19.

Nisbett, R. E., \& Wilson, T. D. (1977). Telling More Than We Can Know: Verbal Report on Mental Processes. Psychological Review, 84 (3), 231-259.

Oberwittler, D., \& Wikström, P.-O. (2009). Why Small is Better: Advancing the Study of the Role of Behavior Contexts in Crime Statistics. In D. L. Weisburd, W. Bernasco \& G. Bruinsma (Eds.), Putting Crime in Its Place: Units of Analysis in Geographic Criminology (pp. 35-59). Springer, New York.

Pettiway, L. (1982). Mobility of Robbery and Burglary Offenders - Ghetto and Nonghetto Spaces. Urban Affairs Review, 18 (2), 255-270.

Pyle, G., Hanten, E., Williams, P., Pearson, A., \& Doyle, G. (1974). The spatial dynamics of crime. University of Chicago, Chicago.

Rengert, G. (2004). The journey to crime. In G. Bruinsma, H. Elffers \& J. De Keijser (Eds.), Punishment, Places and Perpetrators: Developments in Criminology and Criminal Justice Research (pp. 169-181). Willan Publishing, Cullompton. 
Rengert, G., \& Wasilchick, J. (1985). Suburban Burglary: A Time and Place for Everything. Thomas, Springfield, IL.

Rubin, D. B. (1987). Multiple Imputation for Nonresponse in Surveys. Wiley \& Sons, New York.

Rushton, G. (1969). Analysis of spatial behavior by revealed space preference. Annals of the Association of American Geographers, 59 (2), 391-400.

Sarangi, S., \& Youngs, D. (2006). Spatial patterns of Indian serial burglars with relevance to geographical profiling. Journal of Investigative Psychology and Offender Profiling, 3 (2), 105115.

Shaw, K. T., \& Gifford, R. (1994). Residents' and Burglars' Assessment of Burglary Risk from Defensible Space Cues. Journal of Environmental Psychology, 14 (3), 177-194.

Smith, W., Bond, J., \& Townsley, M. (2009). Determining How Journeys-to-Crime Vary: Measuring Inter- and Intra-Offender Crime Trip Distributions. In D. Weisburd, W. Bernasco \& G. Bruinsma (Eds.), Putting Crime in Its Place: Units of Analysis in Geographic Criminology (pp. 217-236). Springer, New York.

Summers, L. (2012). The Role of Place in Outdoor Serious Violence. University College London, London.

Taylor, M., \& Nee, C. (1988). The Role of Cues in Simulated Residential Burglary: A Preliminary Investigation. British Journal of Criminology, 28 (3), 396-401.

Townsley, M., Birks, D., Bernasco, W., Ruiter, S., Johnson, S. D., White, G., \& Baum, S. (2014). Burglar Target Selection: A Cross-national Comparison. Journal of Research in Crime and Delinquency, $52(1), 3-31$.

Townsley, M., Birks, D., Ruiter, S., Bernasco, W., \& White, G. (2015). Target Selection Models with Preference Variation Between Offenders. Journal of Quantitative Criminology, 1-22.

Train, K. E. (2009). Discrete Choice Methods with Simulation (2 ed.). Cambridge University Press, New York.

Turner, S. (1969). Delinquency and distance. In T. Sellin \& M. Wolfgang (Eds.), Delinquency: Selected Studies (pp. 11-26). Wiley, New York.

Van Daele, S. (2009). Itinerant crime groups: mobility attributed to anchor points? In M. Cools, S. De Kimpe, B. De Ruyver, M. Easton, L. Pauwels, P. Ponsaers, G. Vande Walle, T. Vander Beken, F. Vander Laenen \& G. Vermeulen (Eds.), Contemporary issues in the empirical study of crime (Vol. 1, pp. 211-225). Maklu, Antwerp.

Van Koppen, P., \& Jansen, R. (1998). The road to robbery: travel patterns in commercial robberies. British Journal of Criminology, 38 (2), 230-246.

Vandeviver, C. (2014). Applying Google Maps and Google Street View in environmental criminological research. Crime Science, 3 (13), 16.

Vandeviver, C., Van Daele, S., \& Vander Beken, T. (2015). What Makes Long Crime Trips Worth Undertaking? Balancing Costs and Benefits in Burglars' Journey to Crime. British Journal of Criminology, 55 (2), 399-420.

Wiles, P., \& Costello, A. (2000). The 'Road to Nowhere': the Evidence for Travelling Criminals. Home Office, London.

Wright, R., \& Decker, S. (1994). Burglars on the job: Street life and residential breakins. Northeastern University Press, Boston.

Wright, R., \& Logie, R. H. (1988). How Young House Burglars Choose Targets. The Howard Journal of Criminal Justice, 27 (2), 92-104.

Wright, R., Logie, R. H., \& Decker, S. H. (1995). Criminal Expertise and Offender Decision Making: An Experimental Study of the Target Selection Process in Residential Burglary. Journal of Research in Crime and Delinquency, 32 (1), 39-53.

Wu, L., Liu, X., Ye, X., Leipnik, M., Lee, J., \& Zhu, X. (2015). Permeability, space syntax, and the patterning of residential burglaries in urban China. Applied Geography, 60, 261-265.

Ye, X., Xu, X., Lee, J., Zhu, X., \& Wu, L. (2015). Space-time interaction of residential burglaries in Wuhan, China. Applied Geography, 60, 210-216. 
Zipf, G. K. (1949). Human Behavior and the Principle of Least-Effort: An Introduction to Human Ecology. Hafner Publishing Company, New York. 